\title{
Causal attributions of mental health problems and depressive symptoms among older Somali refugees in Finland
}

\author{
Saija Kuittinen \\ University of Tampere, Finland
}

Mulki Mölsä

University of Helsinki, Finland

Raija-Leena Punamäki

University of Tampere, Finland

Marja Tiilikainen

University of Helsinki, Finland

Marja-Liisa Honkasalo

University of Turku, Finland

\section{Corresponding author:}

Saija Kuittinen

School of Social Sciences and Humanities/Psychology

33014, University of Tampere, Kalevantie 5, Finland.

E-mail: saija.kuittinen@gmail.com

Authors' copy. Causal attributions of mental health problems and depressive symptoms among older Somali refugees in Finland. Transcultural psychiatry. 2017. 54(2): pp. 211-238. Copyright ( 2017. DOI: http://dx.doi.org/10.1177/1363461516689003 . Reprinted by permission of SAGE Publications. 


\begin{abstract}
Causal attributions of mental health problems play a crucial role in shaping and differentiating illness experience in different sociocultural and ethnic groups. The aims of this study were (1) to analyze older Somali refugees' causal attributions of mental health problems; (2) to examine the associations between demographic and diagnostic characteristics, proxy indicators of acculturation, and causal attributions; and (3) to analyze the connections between causal attributions and the manifestation of somatic-affective and cognitive depressive symptoms. A sample of 128 Somali refugees aged 50-80 living in Finland were asked to list the top three causes of mental health problems. Depressive symptoms were analyzed using the Beck Depression Inventory. The results showed that the most commonly endorsed causal attributions of mental health problems were jinn, jealousy related to polygamous relationships, and various life problems. We identified five attribution categories: (a) somatic, (b) interpersonal, (c) psychological, (d) life experiences, and (e) religious causes. The most common causal attribution categories were life experiences and interpersonal causes of mental health problems. Men tended to attribute mental health problems to somatic and psychological causes, and women to interpersonal and religious causes. Age and proxy indicators of acculturation were not associated with causal attributions. Participants with a psychiatric diagnosis and/or treatment history reported more somatic and psychological attributions than other participants. Finally, those who attributed mental health problems to life experiences (e.g., war) reported marginally fewer cognitive depressive symptoms (e.g., guilt) than those who did not. The results are discussed in relation to biomedical models of mental health, service use, immigration experiences, and culturally relevant patterns of symptom manifestation.
\end{abstract}

Keywords: causal attributions, explanatory models, mental health, depressive symptoms, refugees, Somalis 
Subjective experiences and explanations of illness and wellbeing are shaped by sociocultural contexts, and therefore vary greatly across time and living environments (Desjarlais, Eisenberg, Good, \& Kleinman, 1997; Kleinman, Eisenberg, \& Good, 1978; Weiss \& Somma, 2007). In addition to culture and social situations, demographic characteristics and lifespan events are also important determinants of health experience and explanation. For example migrants and refugees who come into contact with new cultural practices and beliefs and are exposed to specific and stressful life events through their migration experiences might both adhere to common attributions in their culture of origin as well as finding new ways of explaining illnesses (Caplan et al., 2011; Carroll, 2004).

Causal attributions explain why people get sick or suffer from various problems, and form part of broader explanatory models of illness which include conceptions about adequate help, probable outcomes (Weiss \& Somma, 2007), and health related behaviors (Kleinman, 1980; McCabe \& Priebe, 2004; Palmer, 2006). Causal health attributions are also associated with manifestations of somatic and psychological symptoms, with some studies reporting psychological attributions among patients with mood and anxiety disorders, and somatic attributions among patients with physical symptoms (Duddu, Isaac, \& Chaturvedi, 2006). It is thus possible that causal mental health attributions are associated with specific ways of manifesting psychological distress. Information about culturally salient causal attributions among migrant populations is therefore vital for providing efficient health services in multicultural societies (Bhui \& Bhugra, 2002). In this paper, we focus on causal attributions of mental health problems among older Somali (over 50 years old) ${ }^{1}$ refugees $^{2}$ living in Finland. We examine their attributions of mental health problems and analyze how sex, age, education, diagnostic characteristics, and proxy indicators of acculturation are associated with causal attributions. 
Finally, we analyze the associations between mental health attributions and depressive symptom manifestation.

\section{Causal Attributions of Mental Health Problems}

Subjective illness experiences (Eisenberg, 1977; Kleinman et al., 1978) are intrinsically embedded in larger social systems that shape how ill health and distress are named, explained, and cured, and can therefore be understood as culturally constructed (Arthur \& Whitley, 2015; Dein, Alexander, \& Napier, 2008). Conceptions of underlying causes for mental health problems are connected with what is considered effective treatment (Ahn, Proctor, \& Flanagan, 2009; Sorsdahl, Flisher, Wilson, \& Stein, 2010), and thus also with help seeking behaviors. Researchers agree that a "service gap" or "paradox" exists among refugees. Although refugees show typically high levels of mental health problems due to their stressful life experiences (Fazel, Wheeler, \& Danesh, 2005), they use mental health services significantly less than native or other migrant populations in many European countries (Gerritsen et al., 2006; McCrone et al., 2005), including Finland (Castaneda et al., 2012). Research among Somali origin migrants in Finland reveals that some are unsatisfied with Finnish mental health services and prefer to travel and seek help instead from Somalia (Tiilikainen \& Koehn, 2011). Some Somali origin migrants suffering from mental health problems are also forcibly returned to Somalia by their families in order to get treatment (Tiilikainen, 2011).

Some researchers have conceptualized causal mental health attributions according to the role of the individual versus community in illness onset by using terms such as impersonal versus personalistic causes (Eisenbruch, 1990), situation-centered versus individual-centered causes (e.g., White, 1982), and cosmocentric versus anthropocentric health views (Sterlin, 2006). The common underlying notion in these conceptualizations is the relative importance and 
responsibility of the individual for the onset of illness. Impersonal/situational causes and the cosmocentric view attribute sickness and distress to factors outside the individual (e.g., religion, living environments), whereas personalistic/individual-centered causes and the anthropocentric view locate causal factors within the person (e.g., genes, personality).

Common attributions among various groups of African, Caribbean, and Asian origins relate to material and social factors, such as interpersonal problems and poverty (Aidoo \& Harpham, 2001; McCabe \& Priebe, 2004), and to the spiritual world and religion (Lim, Hoek, \& Blom, 2015; Sorsdahl et al., 2010). Causal attributions often involve several potential causes simultaneously; however, biomedical explanations are less common outside Western contexts (Carrol, 2004; Lawrence et al., 2006). In contrast, research among experts of Western psychiatry reveals that most attribute disorders such as schizophrenia and bipolar disorder primarily to biomedical factors, and not by a combination of biomedical, psychological, or environmental variables (Ahn et al., 2009).

\section{Views on Mental Health in Finland and Somalia}

The Somali participants of this study live in Finland, where biomedical attributions play a central role in the conceptualization of mental health problems and their subsequent treatments. A study among Finnish laypeople, nurses, doctors, and members of parliament showed that more than $80 \%$ of respondents in all groups considered schizophrenia to be a disease, situating schizophrenia next to cancer and diabetes on the disease scale (Tikkinen et al., 2013). Similarly, the majority considered depression to be a medical state, which was evaluated as more of a disease than, for example, high blood pressure or a hip fracture.

Somalia is an East African country with influences of Islamic and Arabic traditions (Cassanelli, 2010; Lewis, 1998), where the social world occupies a central position for wellbeing. 
Illnesses are commonly attributed to various life problems and social, religious, and spiritual phenomena (Carroll, 2004; Pavlish, Noor, \& Brandt, 2010; Tiilikainen, 2010). Spirits continue to be significant factors in the ways that people make meaning of illness and suffering; however, owing to socio-political changes following the prolonged civil war, ideas concerning different categories of spirits have changed. For example, spirits previously commonly known saar (or zar) and their related rituals are nowadays often seen as being against Islam, whereas jinn (or djinn) — invisible spirits or beings created by Allah and presented in the Koran (Dein, Alexander, \& Napier, 2008)—cannot be denied (Tiilikainen, 2010).

Previous studies in the U.S. (Carroll, 2004), Australia (Fozdar, 2009), Sweden

(Johnsdotter, Ingvarsdotter, Östman, \& Carlbo, 2011), and Finland (Mölsä, Hjelde, \& Tiilikainen, 2010) have confirmed that Somali immigrants consider the social world and pre- and postimmigration life experiences (e.g., war, discrimination) to be important influences on mental wellbeing. Because many problems are seen to originate in the social and spiritual worlds, effective healing implies changes in the relevant external conditions and adherence to social network, traditional healers, and religion (Carroll, 2004; Guerin, Guerin, Diiriye, \& Yates, 2004). Instead of recognizing a dualistic division between mental and somatic problems, Somali medicine sees health in a holistic way. Notions related to causes, expressions, and illness categories of mental distress are intertwined and overlapping, and they do not converge with Western psychiatric nosology. For example, murug (sadness), waalli (madness), and jinn may be seen as causal factors for mental distress and as illness categories (Carroll, 2004). Although waalli is usually considered a mental health problem, it is not considered a disease, that is, abnormal functioning of the body or brain. Instead, Somalis often attribute waalli to jinn, to difficult life experiences, or to strong emotional states that are not resolved appropriately (Mölsä et al., 2010). 
Studies indicate that Somali origin migrants also see mental health suffering on a continuum without clear-cut distinctions between different mental disorders (Johnsdotter et al., 2011; Loewenthal, Mohamed, Mukhopadhyay, Ganesh, \& Thomas, 2012). For example, emotional suffering or feelings of anxiety are not considered mental health problems, but natural reactions to adversities in life. However, when strong emotions and their causes are not solved properly, they can lead to waalli, which is associated with socially disturbing behavior and inability to take care of everyday tasks such as personal hygiene (Tiilikainen, 2003; Carroll, 2004). Recovery from waalli is unlikely, making suffering from mental health problems frightening and stigmatizing (Carroll, 2004; Guerin et al., 2004; World Health Organization, 2010). Strong emotional experiences that can lead to waalli include, for example, welwel (worry), niyadjab or qalbijab (demoralization and sadness due to disappointment), and murugo (sadness; Tiilikainen 2003; Carroll, 2004). In addition, some forms of emotional distress are gendered. Buufis (sadness and distress related to migration experience involving, for example, poor appetite and insomnia) are common among men, and maseyrka (a strong emotional experience of envy and jealousy stemming from polygamous relationships) mainly affects women (Mölsä et al., 2010).

Empirical research among Somalis in the U.S. highlights that the mismatch between Somali and Western ways of perceiving mental health is associated with Somalis' reluctance to seek help from medical practitioners (Carroll, 2004). Additionally, in a Swedish study, Somalis expressed their unwillingness to use the available psychiatric services (Johnsdotter et al., 2011). According to ethnographic research in Finland, Somalis value Finnish health care in general, but they consider the mental health services inappropriate (Mölsä et al., 2010; Somalis in Helsinki, 2013) and feel that health care professionals often lack understanding of their situation and needs, partly due to cultural differences in ways of understanding illnesses (Somalis in Helsinki, 2013). 
Many Somali origin migrants have also adopted some health views that are common in their new resettlement country. For example, symptoms that Somalis could have previously attributed to evil eye may in Finland be seen as symptoms of allergies or lactose intolerance (Mölsä et al., 2010; Somalis in Helsinki, 2013).

Previous studies about Somali mental health conceptions have often focused on in-depth information collected mainly by qualitative methods such as focus group interviews (Carroll, 2004; Johnsdotter et al., 2011; Loewenthal et al., 2012; Mölsä et al., 2010; Palmer, 2006). Although these studies provide us with valuable information, it is also important to study mental health views among Somalis with larger samples. Group interviews can be problematic because some responses may be affected by conformity, and divergent views may remain hidden, especially since mental health is a sensitive topic in Somali communities. Causal mental health attributions can also be subject to important intra-group variation. Therefore, it is important to study how demographic factors such as age, sex, and education are associated with mental health attributions. Furthermore, in the context of immigration, it is necessary to consider the possible influences of living in the new country of settlement and being in contact with the local health conceptions. In this study, we focus on older Somali refugees and apply an approach that enables analysis of the role of relevant demographic and diagnostic characteristics and acculturation proxies in causal attributions.

\section{Mental Health Attributions and Psychiatric Symptom Manifestation}

Besides service use and satisfaction with services, the way people understand and perceive mental distress may impact their ways of manifesting symptoms. Many studies have reported cultural differences in psychiatric symptom manifestation (e.g., Ballenger et al., 2001; Simon, VonKorff, Piccinelli, Fullerton, \& Ormel, 1999); however, evidence is more limited about how 
culture shapes psychopathology and brings about variations across ethnic and linguistic groups (e.g., Ryder et al., 2008). According to Shorter (1993), different sociocultural environments can affect the way suffering is communicated by defining a certain number of relevant symptoms, or a "symptom pool", that resonates with the ideas of the surrounding community. This mechanism, albeit unconscious, helps individuals to express their suffering to others in an understandable and meaningful way. For example, a retrospective study in Egypt found that the manifestation of psychiatric symptoms with religious content followed societal changes in religious emphasis, thus reflecting "the prevalence of normal symbols and expressions in the larger society" (Atallah, El-Dosoky, Coker, Nabil, \& El-Islam, 2001, p. 414).

In this study, we examined whether type of causal mental health attribution is associated with the manifestation of depressive symptoms. Depression is estimated to be the most prevalent psychiatric disorder worldwide (Bromet et al., 2011) causing a considerable burden of disease (Moussavi et al., 2007). However, variations in depressive symptoms can make it challenging to identify depression in different settings worldwide. A study among the same Somali participants as in the current study and match-paired native Finns revealed that Somali refugees reported more somatic-affective depressive symptoms (e.g., somatic preoccupation, low affect) than Finns, who instead reported higher levels of cognitive depressive symptoms (e.g., self-dissatisfaction, guilt) (Kuittinen, Punamäki, Mölsä, Saarni, Tiilikainen, \& Honkasalo, 2014). These results are in line with other studies confirming that the rates of manifested somatic and psychological depressive symptoms vary across different sociocultural groups. In many industrialized countries in the Western world, specifically in North America and Western Europe, salient depressive symptoms include feelings of worthlessness, self-blame, and guilt (e.g., Draguns \& TanakaMatsumi, 2003). In many other cultural contexts (Ballenger et al., 2001), including some Muslim societies (Al-Issa, 2000; Bhui et al., 2003), these psychological and individual-focused symptoms 
are less common. Instead, common expressions of distress in these contexts often include general discomfort and pains.

The role of cultural illness conceptions and attributions could help explain some of the variation in depressive symptoms. In Somali culture, causes of mental health problems are commonly located outside the individual — in social relationships or the surrounding environment (Guerin et al., 2004) — and therefore, individual-focused symptoms placing the person in the center of suffering may not be meaningful or appropriate ways of experiencing and communicating distress. Other factors such as mental health stigma in Somali culture (Tiilikainen 2003; WHO, 2010) may also inhibit verbalizing psychological distress, thus shaping symptom manifestation.

\section{Context of the Study and Research Questions}

We focused on causal attributions of mental health problems among older Somali refugees living in Finland. An estimated 1-1.5 million Somalis live in the diaspora (Hammond et al., 2011). Accordingly, Somalis are one of the largest migrant groups and ethnic minorities in Europe (Somalis in Helsinki, 2013), including in Finland (Statistics Finland, 2013a).

Finland is a Nordic country with a relatively homogenous population. In 2012, the number of foreign residents calculated by the number of foreign language speakers was 267,000 , which is approximately $5 \%$ of the total population (Statistics Finland, 2013a). Somalis $(14,800)$ were the third biggest foreign language group after Russians $(62,500)$ and Estonians $(38,400)$. Somalis are therefore not only the largest African origin group but also the largest ethnic group with a refugee background and the largest Muslim group in Finland. Many have reported difficulties in integrating in Finnish society because of experiences of racial discrimination and harassment 
(Jasinskaja-Lahti, Liebkind, \& Perhoniemi, 2006; Somalis in Helsinki, 2013). In addition, the unemployment rate among Somalis has been very high; for example, more than $50 \%$ in 2008 (Statistics Finland, 2010).

The majority of Finnish Somalis are young. In 2013, more than 60\% were under 25 years old (Statistics Finland, 2013b). Although studies among Somalis have increased in the past 10 years in Finland, research among older Somalis is lacking (Mölsä \& Tiilikainen, 2008). Information about factors associated with older migrants' and refugees' mental health is needed, as they can be especially vulnerable to depression and other mental health problems (Abu-Bader, Tirmazi, \& Ross-Sherif, 2011; Silveira \& Ebrahim, 1995) that increase their need for services. In Finland, the State provides public health care and social services to all permanent residents. Public health care centers receive all residents in the corresponding area, and permanent health care services designed for migrants and refugees are very few, except for one psychiatric clinic for immigrants and two centers for victims of torture.

We aimed to answer two research questions: (1) What are the most common causal attributions of mental health problems among older Somali refugees? (2) How are demographic (sex, age, and education) and diagnostic (psychiatric diagnosis and/or treatment history) characteristics and proxy indicators of acculturation (Finnish nationality, time in Finland, and Finnish language proficiency) associated with mental health attributions?

Concerning the relationships between causal attributions and depressive symptom manifestation, we hypothesized that: (1) Intra-individual causal attributions (e.g., excessive worrying) are associated with more frequent cognitive depressive symptoms (e.g., guilt) and with fewer somatic-affective symptoms (e.g., low affect); and (2) Life experience attributions (e.g., war, poverty) are associated with fewer cognitive depressive symptoms and with more frequent 
somatic-affective symptoms. We did not have a hypothesis concerning depressive symptom manifestation and religion because socio-religious attributions may involve both individual responsibilities and community affiliation.

\section{Method}

\section{Participants and Procedure}

The study participants were 128 Somalis aged between 50 and 80 years, all born in Somalia and living in the Helsinki metropolitan area. According to the Population Register Center, 307 older (>50 years) Somalis were living in the area in 2006. Of these 307 individuals, every second person was randomly chosen $(n=155)$. Fifteen of the chosen individuals were excluded due to hospitalization or absence, and two had passed away. Participants were contacted by phone and information letters, as well as through social networks and mosques, cultural centers, language classes, and coffee shops. Ten of the remaining 138 eligible participants refused to participate, leaving a final sample of 128 participants, for response rate of $93 \%$.

The second author (a native Somali speaker) and a social psychologist trained and supervised eight Somali speaking research assistants, three women and five men, who carried out the research visits in 2007. The majority of Somali women chose to meet in their homes, while men preferred some of the common meeting places within the Somali community. Because of the high illiteracy rate (48\%), all the questions were read aloud and the answers were written by the research assistants. All the research visits were conducted in the Somali language and lasted an average of two hours. The interview included questions about the participants' pre- and postmigration experience, religiousness, health practices, mental health symptoms, and causal attributions of mental health problems. In this study, we focus on analyzing depressive symptoms and causal attributions of mental health problems. Other findings have been reported elsewhere 
(Kuittinen et al., 2014; Mölsä, Punamäki, Saarni, Tiilikainen, Kuittinen, \& Honkasalo, 2014; Mölsä, Kuittinen, Tiilikainen, Honkasalo, \& Punamäki, 2016). Prior to fieldwork, a pilot test was carried out with ten Somali volunteers aged over 50.

\section{Measures}

Demographic characteristics. Data were collected on participants'sex, age, civic status, education, and employment status. Age was classified into three classes: 50-59; 60-69; and 7080 years. Civic status was recorded as married, divorced, widowed, or single. Education was divided into three classes: none; vocational training/some courses; and university/polytechnic education. Employment status options were full time employment, part time employment, unemployed, retired, or other.

Diagnostic characteristics. Participants were asked whether they had been diagnosed with a psychiatric disorder (specific diagnoses of either psychosis, depression, anxiety, or substance abuse) and whether they had been hospitalized, received medication, or visited a doctor due to the disorder. For the statistical analyses, we formed a single dichotomous variable of psychiatric diagnosis and/or treatment history $(0=$ no psychiatric diagnosis and no treatment history; 1 = yes, a psychiatric diagnosis and/or treatment history).

Proxies of acculturation. To analyze the role of living in Finland, we used three proxy indicators of acculturation: current residency status; time spent in Finland; and language proficiency. For the purposes of statistical analyses participants were categorized either as Finnish citizens or not . In order to obtain Finnish nationality, applicants must have satisfactory knowledge of Finnish or Swedish (the other official language in Finland) and have lived in Finland at least four or five years (depending on the nationality of the spouse). Time spent in 
Finland (in years) was divided into three classes: 0-5 years, 6-10 years, and 11-20 years. Finnish language proficiency was categorized as not knowing any Finnish or having at least basic knowledge of the language.

Depressive symptoms. Symptom manifestation was assessed by the Beck Depression Inventory (BDI; Beck, Ward, Mendelson, Moc, \& Erbaugh, 1961). The BDI is a 21-item scale with statements related to depressive mood, thoughts, and behavior and response categories that range in severity (e.g., "I do not feel sad," "I feel sad," "I am sad all the time, and I can't snap out of it," "I am so sad or unhappy that I can't stand it") scored on a 4-point scale from 0 to 3 . These are summed to yield an overall score from 0 to 63 . Common cut-off scores according to the severity of depression are 0-9 indicating no depression, 10-18 indicating mild-to-moderate depression, and >19 indicating moderate-to-severe depression (Beck et al., 1961). In a previous study involving the same Somali sample and a matched-pair Finnish sample, two BDI symptom manifestation categories were identified through factor analysis: somatic-affective and cognitive symptoms (Kuittinen et al., 2014).

Causal mental health attributions. To indicate causal mental health attributions, the participants were asked to state the three most important causes for mental health problems without ranking the causes in importance. The generic term "mental health problems" was chosen because of the discrepancies between psychiatric terminology in Somali and Finnish/English. The analysis proceeded in three stages. First, all responses were listed and conceptual categories underlying the responses were identified through content analysis. Second, the emerging categories were named, in part based on an earlier study that identified causes related to social environment, personal characteristics, interpersonal relationships, biological factors, and spiritual factors (Phillips, Li, Stroup, \& Xin, 2000) ${ }^{3}$. We therefore derived five attribution categories depicting (a) somatic, (b) interpersonal, (c) psychological, (d) life experiences, and (e) religious 
causes.

In the third stage, two raters (the first author and a social psychologist) classified all the single responses into the five attribution categories. The attribution categories were formed as follows: (a) the somatic attributions category consisted of answers related to insomnia, somatic problems (e.g., diabetes, migraine), and substance use (e.g., alcohol, khat ${ }^{4}$ ). (b) The interpersonal attributions category comprised answers relating to social networks and relationships with others (e.g., family problems, loneliness) and maseyrka (jealousy due to polygamous relationships). Classification decisions were based on the principal character of the responses. For example, although maseyrka describes an individual emotional experience, it was classified as an interpersonal cause because it is intrinsically related to family and social relationships. Curses and sorcery were classified as interpersonal causes in line with their meaning in East African contexts and Somali culture, where they are associated with powerful people within one's social network (Helander, 1995; Reynolds Whyte, 1997). (c) The psychological attributions category consisted of answers depicting one's emotional experience (e.g., sadness, worrying) and cognitivebehavioral responses (e.g., excessive thinking, gambling). (d) The life experiences category comprised answers relating to the living environment and life experiences, such as poverty, war, hard life, and loss of property. (e) The religious attributions category included answers referring to God, God's will, and losing one's religious belief. Jinn were also classified as religious causes, as they are thought to be created by God and are presented in the Koran (Dein et al., 2008; Lim et al., 2015). Because waalli often describes "madness" and not causes for it, answers of waalli could not be classified into any of the five attribution categories and were thus excluded from further statistical analyses using the attribution categories ${ }^{5}$.

The values of each attribution category ranged from 0 to 3 , because the participants reported three causes that were classified into the attribution categories. For example, the value 
of interpersonal attribution category was 0 , if the participant reported no causes that were classified as interpersonal. If the participant reported one or more causes that were classified as interpersonal (e.g., loneliness, maseyrka, or family problems), the value of the interpersonal attribution category was 1,2 , or 3 , according to the number of reported interpersonal causes. When the raters failed to agree on the classification, it was decided based on discussion or according to the first rater's (the first author) opinion. The inter-rater agreement of the blind coding (Kappa) was high, reaching 0.91.

Finally, in order to analyze the associations between attribution categories, demographic and diagnostic characteristics, acculturation proxies, and depressive symptom manifestation, we formed three wider attribution categories from the five categories. The first category combined interpersonal and religious causes into one category labeled socio-religious causes, including all answers related to interpersonal relationships, jinn, and God. This decision was based on traditional Somali medicine, which sees health as relational and dependent on balance in the social world and on one's relation to God, spirits, and other humans (Slikkerveer, 1990, p. 167). The second category combined psychological and somatic causes into one category that was labeled intra-individual causes reflecting psychological and physical factors located inside the individual. This is in line with holistic health views in Somali culture that contradict dualistic divisions between psychological and physical factors. Finally, the third category included the same life experiences attributions (e.g., war, poverty) as those used in the division of the five categories.

\section{Data Analysis}

The data was analyzed with SPSS statistical software (version 22; IBM Corporation, 2013). Demographic and diagnostic characteristics were analyzed with descriptive statistics (frequencies 
and percentages). The categorization of somatic-affective and cognitive depressive symptoms was done using a Direct Oblimin rotated principal factor analysis. The reliability of the blind classification of causal attributions into attribution categories was statistically analysed by the Kappa coefficient. Spearman correlations were used to test the correlations between different causal attribution categories. Chi square tests were used to test the association between demographic and diagnostic characteristics, proxies of acculturation and causal attribution categories. The association between depressive symptoms and causal attribution categories was analyzed using the Mann-Whitney test.

\section{Results}

\section{Descriptive Statistics}

Table 2 presents the demographic information of the participants' sex, age, civic status, education, employment status, and proxy indicators of acculturation. Of the participants, who ranged in age from 50 to 80 years, $59 \%$ were women $(M=57.90, S D=.50)$. Most participants reported having no formal schooling, and more than half were either unemployed or retired.

About a half (48\%) reported being illiterate. Approximately half (48\%) indicated no knowledge of Finnish, while only 14 participants (11\%) indicated having good language proficiency. Slightly more participants (12\%) reported knowing some English, whereas no one knew Swedish, the other main official language in Finland.

The sum score of depressive symptoms varied between 0 and 30. Approximately half of the participants $(56 \%, \mathrm{n}=71)$ indicated having no depression, a quarter $(25 \%, \mathrm{n}=31)$ had mildto-moderate depression, and $19 \%(\mathrm{n}=24)$ reported having moderate-to-severe depression. In order to analyze the manifestation of specific depressive symptoms we conducted a Direct Oblimin (oblique) rotated principal axis factor analysis ${ }^{6}$ (see Table 1). According to the factor solution, two symptom categories, cognitive depressive symptoms and somatic-affective 
depressive symptoms, were formed. The cognitive depressive symptom category included seven items about negative feelings and ideas about self: sense of failure, dissatisfaction, guilt, selfdislike, self-blame, suicidal ideation, and body image change. Somatic-affective symptoms included 14 items about lowered mood, lack of motivation, and somatic discomforts: depressed mood, hopelessness, feeling of punishment, crying, irritability, lack of interest in others, difficulty making decisions, difficulty working, insomnia, fatigue, lack of appetite, weight loss, worry about health, and lack of interest in sex. The factor intercorrelation was .32 and the factors had adequate or good internal reliabilities (Table 1).

Overall, 17 participants (10 women, seven men; 13\%) had been diagnosed with and/or received psychiatric treatment because of a mental health problem. There were 11 diagnoses of psychosis, six of depression, nine of anxiety, and one substance abuse problem, thus indicating comorbid problems. Six of the respondents had been hospitalized and four had received medication for their condition. During the 12 months prior to the study, five participants (4\%) had seen a doctor at least once because of psychiatric distress.

Insert Table 1 about here

Insert Table 2 about here

\section{Distribution of Mental Health Attributions}

In total, the participants gave 336 answers on potential causes of mental health problems. The five most commonly endorsed single causes were jinn $(n=52)$, maseyrka (jealousy related to polygamous relationships in particular; $n=41$ ), general unspecified problems and difficulties in life $(n=30)$, poverty $(n=24)$, and war $(n=21)$. Waalli (madness) was stated as a cause for mental health problems by 11 participants, and 9 attributed mental health problems to God. A few answers referred to a strong emotional experience, for example, fear $(n=6)$, shock $(n=5)$, 
and murugo (sadness; $n=4)$. Uncommon single causes were sorcery $(n=1)$, curse $(n=2)$, welwel (worry; $\mathrm{n}=2$ ), buufis (sadness and distress related to migration experience; $\mathrm{n}=2$ ), brain chemistry $(n=1)$, brain disease $(n=3)$, and syphilis $(n=2)^{7}$.

These single causes (with the exception of waalli) were classified into five attribution categories. Table 3 presents examples of the answers in each attribution category and their prevalence (frequencies and percentages) among all respondents. The most common attribution categories were life experiences and interpersonal relationships, endorsed by $57 \%$ and $52 \%$ of the participants, respectively. As can be seen in the correlations between different attribution categories (Table 4), the categories did not overlap significantly (i.e., show positive correlations), with the exception of interpersonal and religious attributions, which correlated positively (r $=.250, p<.01)$. The significant positive correlation between interpersonal and religious attributions (Table 3) thus supported our decision to combine interpersonal and religious causes into socio-religious causes category.

Insert Table 3 about here Insert Table 4 about here

Table 5 shows the frequencies and percentages of the three attribution categories (socioreligious, intra-individual, and life experiences) according to sex, age, education, diagnostic characteristics, and proxy indicators of acculturation. Women and men differed in their causal attributions of mental health problems. Intra-individual attributions were more common among men (59\%), while socio-religious attributions were more frequent among women (72\%). Education was marginally associated $(p<.10)$ with two attribution categories. Life experience attributions were more common among participants with a university level education (82\%) than among those who had only vocational level education (52\%) or among those with no formal schooling at all (54\%). Intra-individual attributions were less common among participants with 
vocational level schooling (22\%) than among those with no formal schooling (42\%) or university education (59\%). Age and proxy indicators of acculturation were not associated with the attribution categories. Finally, two thirds $(65 \%, 11 / 17)$ of the participants with a psychiatric diagnosis and/or past treatment history endorsed intra-individual and life experiences attributions, and almost half $(47 \%, 8 / 17)$ endorsed socio-religious attributions. Intra-individual attributions were more common among participants with a psychiatric diagnosis and/or treatment history than among other participants.

Insert Table 5 about here

\section{Causal Attributions and Depressive Symptom Manifestation}

To test the associations between attribution categories and somatic-affective and cognitive depressive symptoms, we formed dichotomous variables of socio-religious, intra-individual, and life experiences attribution categories. Owing to non-normality in the data, we ran pairwise nonparametric comparisons between each attribution category and somatic-affective and cognitive depressive symptoms. Associations between intra-individual attributions and depressive symptoms type were not significant, thus failing to support our first hypothesis. Confirming our second hypothesis, a Mann-Whitney test indicated that participants who attributed mental health problems to life experiences had significantly less cognitive depressive symptoms (mean rank $=$ $57,32$ ) than those who did not (mean rank $=72,35), \mathrm{U}=1521.000, \mathrm{z}=-2.406, p=.016$. However, when controlling for multiple comparisons (False Discovery Rate; Benjamini \& Hochberg, 1995), the result became only marginally significant (10\% significance margins, $p=$ .096). Contrary to the hypothesis, life experiences attributions were not associated with more somatic-affective symptoms. Socio-religious attributions did not have any specific associations with depressive symptoms. 


\section{Discussion}

In this study, we examined on causal attributions of mental health problems of older Somali refugees to better understand their illness experience and shed light on mechanisms that may lead to culturally related ways of manifesting depressive symptoms. Our findings concur with other studies in that the participants generally considered life experiences and religious and social worlds to be the most important determinants of mental health (Carroll, 2004; Pavlish, Noor, \& Brandt, 2010; Tiilikainen, 2010). The two most common single concepts thought to cause mental health suffering were jinn and maseyrka (jealousy related to polygamous relationships), reflecting specific aspects of Somali culture. Other common causal attributions were war, poverty, and having a hard life, highlighting sociopolitical origins of suffering that can be readily shared and understood across cultural settings. Women's and men's experiences have traditionally been very different in Somali culture (Lewis, 2008) and this was reflected in our findings. Women attributed mental health problems to socio-religious factors (interpersonal relations and relationships with jinn and God), while men emphasized intra-individual causes (somatic and psychological factors) for mental health problems. Finnish nationality, time spent in Finland, and Finnish language proficiency were not associated with mental health attributions. Finally, Somalis who attributed mental health problems to life experiences, such as war and poverty, manifested marginally less cognitive depressive symptoms (e.g., guilt, feelings of worthiness) than those who did not.

In general, participants did not endorse biomedical causes (e.g., brain disease, chemical imbalance) for mental health problems, and attributions to heredity or personality (e.g., being sensitive or hostile) were completely absent. Instead, participants' views on the causes of mental health problems were in line with empirical evidence from low-income countries that highlights 
the role of social surroundings and difficult living environments, such as unemployment, hunger, and violence, for mental health (Desjarlais et al., 1996). Although many Somalis face multiple problems in Finland, none of the responses in the present study specifically mentioned postmigration experiences in Finland as possible causes for mental health problems. However, two individuals attributed mental health problems to buufis, which refers to sadness and distress related to migration experience.

While some common traditional illness attributions in Somali culture, such as saar spirits or evil eye, were absent in this study, jinn were very commonly named as a cause of mental illness. The results contrast with earlier findings among Somali origin migrants that have documented saar spirits—often associated with older married women—as relevant mental health attributions (Johnsdotter et al., 2011; Mölsä et al., 2010). The high prevalence of attributions to jinn is in line with studies among various Muslim groups that clearly indicate the relevance of jinn, even in exile (Dein et al., 2008; Lim et al., 2015). The lack of attributions to saar spirits concurs partly with the argument that, in exile, Somalis' views have shifted to match new Islamic interpretations as their knowledge of Islam and general religiosity have increased. This change in perceptions of illness and proper ways of healing is linked to a larger religious-political change in Somalia where Sufi Islamic practices including certain acceptance and understanding of coexistence between humans and spirits are giving way to more puritanistic forms of Islam (Berns McGown, 1999; Tiilikainen, 2010). In other words, traditional ideas on the causes of illnesses or healing practices are changing among Somalis in Finland not only because of their encounters with Finnish health culture and practices, but also because of recent religious-political shifts that have led to new interpretations of Islam in Somalia (Mölsä et al., 2010). Jinn are specifically acknowledged by Islamic theology, contrary to saar or other spirits, and they 
continue to be meaningful and acceptable ways of understanding illness and suffering even after migration, as confirmed by our results.

The sex differences in causal attributions found in our study could be interpreted in line with Eagly's social role theory (1987), which holds that the traditional labor division between men and women involves women taking care of the home and children while men pursue tasks outside the home. According to the theory, this leads women to endorse more traits, needs, or values related to interpersonal relationships, whereas men manifest more traits emphasizing individual agency. In our study, women attributed mental health problems more to interpersonal relations and relationships with jinn and God, and men, to individual factors such as excessive thinking or substance use. Additionally, research from sub-Saharan Africa revealed that supernatural attributions of mental health problems such as spirits are more common among women than men (Ikwuka, Galbraith, \& Nyatanga, 2014).

Education was marginally associated with two attribution categories. First, higher level of education was associated with a tendency to report more attributions related to life experiences (e.g., war). This was also the most common attribution category among all participants. Half of the participants with high education also supported socio-religious causal attributions. Our results thus contradict the general belief that traditional health views fade away with education. Second, highly educated and less educated participants had similar understandings of intra-individual causes for mental health problems. Overall, participants endorsed multiple explanations simultaneously, which were relatively stable regardless of education.

Age and proxy indicators of acculturation were not associated with mental health attributions. The low levels of Finnish language skills and low rates of employment are indicative of the contextual barriers to Somalis' acculturation. Older Somalis may therefore be especially isolated and unfamiliar with many health related views and customs in Finland. Furthermore, the 
small number of attributions to sorcery or curses may reflect older Somalis' experiences and changed social position in Finland. Traditionally in Somalia older people have had a highly valued position in the community and the power to curse-or to bless—others, mainly younger individuals (Helander, 1995). In Finland, however, many may feel that they have lost their authority in the family due to their lack of language skills, a shift in the younger generation's values, or feelings that their knowledge is no longer needed (Mölsä \& Tiilikainen, 2008).

The levels of depressive symptoms among older Somalis reported in this study $(25 \%$ mild-to-moderate depression, $19 \%$ moderate-to-severe depression) are considerably higher than the estimates for the general Finish population. According to large scale national health reports, in 2000, the 12-month prevalence for any depressive disorder was 6.5\% (Pirkola et al., 2005). In 2011, the estimates for severe depressive symptoms and depressive disorder in the past 12 months were $6.5 \%$ and $5.3 \%$, respectively (Suvisaari et al., 2012). When we compared the same Somali participants of the current study with a Finnish sample matched according to gender, age, and education, the Somalis manifested more depressive symptoms than the Finns on average, but the rates of clinical depression did not differ between the two groups (Mölsä et al., 2014).

In spite of the high levels of reported symptoms, only 17 participants (13\%) had been diagnosed with a psychiatric disorder and/or received treatment for it. Only five individuals (4\%) had seen a doctor during the 12 months prior to the study. This illustrates the service use gap that is common among refugee populations: despite experiencing depressive symptoms, older Somali refugees rarely seek or receive help from Finnish psychiatric services. Compared to other individuals, those who had been in contact with the Finnish psychiatric service system (diagnosed with and treated for a mental health problem) attributed mental health problems to psychological or somatic causes more often. Being in contact with health care professionals can shape attributions, but it is equally likely that those who attributed problems to inner psychological 
characteristics (e.g., excessive worrying) and somatic health problems (e.g., migraine) may have sought psychiatric help more readily than others.

In Finland, mental health problems are typically conceptualized as biomedical states (Tikkinen et al., 2012). The different mental health views in Finnish and Somali cultures may help to explain why many Somali origin migrants perceive Finnish mental health services as inadequate and prefer not to use them (Tiilikainen \& Koehn, 2011). Nevertheless, cultural differences in causal attributions are only one potential reason for non-usage. Other reasons include language barriers, lack of trust of professionals, availability of services, or the reputation of mental health services among immigrant populations.

\section{Limitations}

This study has important limitations. First, the assessment of psychological distress using the BDI scale reflects cultural ideas of Western psychiatry and might not recognize salient forms of distress among Somalis. However, immigrants in Finland are faced with Western psychiatric services and assessment methods because they use the same services as native Finns. Second, the use of proxy measures to assess acculturation may not capture the complex and multidimensional nature of acculturation processes. Third, we focussed only on causal attributions of mental health problems. A broader and more dynamic assessment of mental health concepts including actual behavior, processes leading to problems, desired outcomes, and views about effective treatment, as proposed, for example, in concepts of "explanatory models" (Kleinman, 1980), "exploratory maps" (Williams \& Healy, 2001), or "illness narratives" (Groleau, Young, \& Kirmayer, 2006), would provide deeper insight into participants' mental health views. As the participants were asked to state the three most important causes for mental health problems, it is possible that some relevant attributions did not come up in this study simply because they were not in the "top three." Further, because of the holistic health views in Somali communities, focusing purely on 
"mental" health may have obscured important issues concerning health beliefs in general. For example, one potential reason we did not find more associations between attribution categories and depressive symptoms could be the absence of attributions to heredity or personality. It would therefore be useful to develop a questionnaire about potential attributions that includes both typical concepts in Somali culture, such as jinn or maseyrka, as well as Western psychiatric concepts including personality traits or biochemical attributions. This would allow the inclusion of more individual-focused attributions and their variations that might be associated with depressive symptoms.

Finally, the cross-sectional study design can only identify associations, not causal relations, between attribution categories and depressive symptoms. The relatively small group sizes in the comparisons and the low power of non-parametric tests may have limited our ability to detect differences. We did not use parametric tests due to non-normality in the data. Future studies with larger samples and more sophisticated statistical methods might better capture the associations between causal attributions and symptom manifestation.

\section{Conclusion}

A common critique of cross-cultural psychology concerns the focus on comparing differences between cultural groups and lack of deeper cultural analyses (Matsumoto \& Yoo, 2006). In order to understand the mechanisms that lead to cultural patterns of psychiatric symptom manifestation, more attention should be paid to "peeling the onion of culture" (Poortinga, Van de Vijver, Joe, \& van de Koppel; 1987) or "unpacking culture" (see, for example, Matsumoto \& Yoo, 2006). In this study, we attempted to explain culturally specific patterns of somatic-affective and cognitive depressive symptom manifestation (Kuittinen et al., 2014) by looking at salient causal attributions of mental health problems. The results suggest that 
causal attributions that locate the origins of mental health problems in factors outside the individual, such as war or poverty, could explain in part the apparent lower frequency of some cognitive depressive symptoms (e.g., guilt, feelings of worthlessness) among older Somalis. The importance of individualistic values and responsibilities common in many Western contexts may contribute to the "psychologization" of depressive symptoms (Ryder et al., 2008). However, these results should be interpreted with caution, because the association between life experience attributions and cognitive depressive symptoms was only marginally significant. Furthermore, there was no association between intra-individual attributions and cognitive depressive symptoms.

Our results clearly indicate the importance of cultural and social phenomena, interpersonal relationships, and extremely stressful life events in determining illness conceptions and subjective suffering among older Somali refugees in Finland. In clinical work, instead of concentrating on aspects of mental health that may seem foreign to practitioners or clients (e.g., specific concepts such as jinn or biomedical models), focusing on socio-political contexts and life-events can serve as a common ground between health care workers and patients from different ethnic and cultural backgrounds. Further research is needed to explore the underlying dynamics of culture and expressions of ill health.

\section{Notes}

${ }^{1} 50$-year-olds are considered old in Somalia, where life expectancy is approximately 54 years (World Bank, 2013).

${ }^{2}$ The target group of this study, older Somali migrants, have mostly come to Finland as asylum seekers or as their spouses through family reunification since the late 1980s. Therefore we chose to refer to the participants as "refugees" although they were not asked about their migration status up on arrival to Finland.

${ }^{3}$ We consulted several studies using different ways of classifying causal mental health attributions (Arthur \& Whitley, 2014; Caplan et al., 2011; Lawrence et al., 2006; McCabe \& Priebe, 2004). The 
categorizations varied according to the method used (e.g., interviews, questionnaires), studied groups, and prevalent answers, but they did not fit our data as well as the categorization described by Phillips and colleagues (2000).

${ }^{4}$ A narcotic leaf consumed in the Horn of Africa, especially in the areas inhabited by Somalis.

${ }^{5}$ After the blind coding, some answers considered ambiguous were tested with different classifications to ensure that the attribution categories did not rely too strongly on one single cause. For example, maseyrka (an interpersonal cause) was classified as a psychological cause because it also describes an emotional experience. We also tested classifying answers of "death" as life experience rather than as an interpersonal cause. Even after making these changes, the associations of attribution categories with demographic characteristics, proxies of acculturation, and depressive symptoms remained the same.

${ }^{6}$ In order to confirm the division of the BDI items into somatic-affective and cognitive categories, we also conducted an exploratory factor analysis (EFA) to see if other possible factor solutions would emerge. The EFA yielded three factors with eigenvalues $>1.00$. Somatic and affective symptoms loaded on the first factor, and other items (cognitive symptoms) loaded on two different factors. However, because there was no theoretical reason for separating these cognitive items into two different factors, we did not change our original two-factor solution (somatic-affective and cognitive symptoms). This decision was supported by the good internal consistency of the final cognitive depressive symptoms factor (Cronbach's alpha .93). Finally, we also tested the associations of attribution categories and depressive symptom manifestation using the same factor analysis solution of the BDI items that was used in the previous study (Kuittinen et al., 2014). This did not change the subsequent results.

${ }^{7}$ The term syphilis is traditionally known in Somalia as a disease that causes nervousness, irritation, and lack of energy. However, the fact that it is a sexually transmitted disease is not widely known among older Somalis (Mölsä et al., 2010). 


\section{Acknowledgement}

The authors are grateful to all the Somali participants who shared their experiences and to our fieldworkers.

\section{Funding}

The research received grants from the Academy of Finland, the Finnish Cultural Foundation, the Finnish Psychiatry Association, and the City of Helsinki.

\section{Biographical Notes}

Saija Kuittinen, MSc, MA, is a psychologist, philologist, and a $\mathrm{PhD}$ candidate at the University of Tampere and National Doctoral Programme of Psychology, Finland. Her research interests focus on cultural, clinical, and developmental psychology. Currently she is finishing her doctoral thesis about mental health among Somali origin migrants in Finland. Simultaneously she works in a research project on parenting and early child development among migrant families in Finland and among families living in Gaza, Palestine. She is a member of the International Association for Cross-Cultural Psychology and the Nordic Network for Research on Refugee Children.

Mulki Mölsä, MD, is a doctoral student at the University of Helsinki, focusing on health and mental health of Somali seniors in Finland. She works as a medical officer at maternity and child health clinics, city of Helsinki, Department of social services and health care, and as a visiting researcher at the National Institute for Health and Welfare (NIHW), Helsinki, Finland. At the NIHW she studies migrants' health, well-being and use of services, as well as the living conditions in Finland. She has also conducted research on female genital cutting and worked as a 
sub-investigator on vaccine clinical trials at the University of Tampere. Her research interests include cross-cultural psychiatry, migration and health, and ageing.

Raija-Leena Punamäki, $\mathrm{PhD}$, is a psychologist and professor of psychology at the University of Tampere, Finland. Her research focuses on family mental health and child and adolescent development in traumatic conditions, especially in war and military violence and among refugees. Her research topics include the role of first-year family dynamics predicting children's social, emotional, cognitive and psychophysiological development, and socio-emotional and cognitive development among war-affected children. Intervention research involves war-affected children, mother-child interaction in life-endangering conditions, and universal preventions among families and children at risk. She is a member of the Finnish Academy of Science and Letters, and the Nordic Network for Research on Refugee Children.

Marja Tiilikainen, $\mathrm{PhD}$, Adjunct Professor in comparative religion, is Academy Research Fellow at the Department of Social Research, University of Helsinki, Finland. She currently works on a research project entitled "Islam and security revisited. Transnational Somali families in Finland, Canada and Somalia”. She has led several research projects on diasporic Somalis and published in particular on everyday Islam, cultural concepts of illness and healing, transnational healing practices and transnational families.

Marja-Liisa Honkasalo, $\mathrm{MD}, \mathrm{PhD}$, is the Director of the Center of the Study for Culture and Health at the University of Turku, Finland. Dr Honkasalo studies conceptual and methodological issues in medical humanities. She has published a series of articles on illness, pain, the body, and death in cultural contexts. Dr Honkasalo received the Steve Volgar Professional Prize from the 
American Anthropological Association for the best article in 2009. Her edited volume Culture, Suicide, and the Human Condition (with Miira Tuominen) was published by Berghahn in 2014. 


\section{References}

Abu-Bader, S. H., Tirmazi, M. T., \& Ross-Sherif, F. (2011). The impact of acculturation on depression among older Muslim immigrants in the United States. Journal of Gerontological Social Work, 54, 425-448. doi:10.1080/01634372.2011.560928

Ahn, W-k., Proctor, C.C., \& Flanagan, E. H. (2009). Mental health clinicians' beliefs about the biological, psychological, and environmental bases of mental disorders. Cognitive Science, 33, 147-182. doi:10.1111/j.1551-6709.2009.01008.x

Aidoo, M., \& Harpham, T. (2001). The explanatory models of mental health amongst low-income women and health care practitioners in Lusaka, Zambia. Health Policy and Planning, 16, 206-213.

Al-Issa, I. (2000). Does the Muslim religion make a difference in psychopathology? In Al-Issa, I. (Ed.), Al-junūn: Mental illness in the Islamic world, pp. 315-353. Madison, CT: International Universities Press.

Arthur, C. M., \& Whitley, R. (2015). "Head take you": Causal attributions of mental illness in Jamaica. Transcultural Psychiatry, 52(1), 115-132. doi:10.1177/1363461514557065

Atallah, S. F., El-Dosoky, A. R., Coker, E. M., Nabil, K. M., \& El-Islam, M. F. (2001). A 22-year retrospective analysis of the changing frequency and patterns of religious symptoms among inpatients with psychotic illness in Egypt. Social Psychiatry and Psychiatric Epidemiology, 36, 407-415.

Ballenger, J. C., Davidson, J. R. T., Lecrubier, Y., Nutt, D. J., Kirmayer, L. J., Lépine, J.P.,...Ono, Y. (2001). Consensus statement on transcultural issues in depression and anxiety from the international consensus group on depression and anxiety. Journal of 
Clinical Psychiatry, 62(Suppl. 13), 47-55.

Beck, A. T., Ward, C. H., Mendelson, M., Moc, J., \& Erbaugh, J. (1961). An inventory for measuring depression. Archives of General Psychiatry, 4(6), 561-571.

Benjamini, Y., \& Hochberg, Y. (1995). Controlling the false discovery rate: A practical and powerful approach to multiple testing. Journal of the Royal Statistical Society. Series B (Methodological), 57(1), 289-300.

Berns McGown, R. (1999). Muslims in the Diaspora: The Somali Communities of London and Toronto. Toronto: University of Toronto Press.

Bhui, K., Abdi, A., Abdi, M., Pereira, S., Dualeh, M., Robertson D.,...Ismail, H. (2003). Traumatic events, migration characteristics, and psychiatric symptoms among Somali refugees. Social Psychiatry and Psychiatric Epidemiology, 38, 35-43. doi:10.1007/s00127-003-0596-5

Bhui, K., \& Bhugra, D. (2002). Explanatory models for mental distress: implications for clinical practice and research. The British Journal of Psychiatry, 181, 6-7. doi:10.1192/bjp.181.1.6

Bromet, E., Andrade, L., Hwang, I., Sampson, N., Alonso, J., de Girolamo, G., . . Kessler, R. (2011). Cross-national epidemiology of DSM-IV major depressive episode. $B M C$ Medicine, 9(90). doi:10.1186/1741-7015-9-90

Caplan, S., Paris, M., Whittemore, R., Desai, M., Dixon, J., Alvidrez, J.,... Scahill, L. (2011). Correlates of religious, supernatural and psychosocial causal beliefs about depression among Latino immigrants in primary care. Mental Health, Religion, and Culture, 4, 589611.

Carroll, J. K. (2004). Murug, Waalli, and Gini: Expression of distress in refugees from Somalia. Primary Care Companion Journal of Clinical Psychiatry, 6, 119-125. 
Cassanelli, L.V. (2010). Speculations on the historical origins of the 'total Somali genealogy'. In Hoehne, M. \& Luling, V. (Eds.), Milk and Peace, Drought and War. Somali Culture, Society, and Politics, pp. 53-66. London: Hurst \& Company.

Castaneda, A.E., Lehtisalo, R., Schubert, C., Halla, T., Pakaslahti, A., Mölsä, M., \& Suvisaari, J. (2012). Mielenterveyspalvelut [Mental health services]. In Castaneda, A. E, Rask, S., Koponen, P., Mölsä, M., \& Koskinen, S. (Eds.) Maahanmuuttajien terveys ja hyvinvointitutkimus venäläis-, somalialais- ja kurditaustaisista Suomessa [Migrant Health and Wellbeing Study], pp. 157-164. Helsinki: National Institute for Health and Welfare.

Dein, S., Alexander, M., \& Napier, D. (2008). Jinn, psychiatry and contested notions of misfortune among east London Bangladeshis. Transcultural Psychiatry, 45, 31-55. doi: $10.1177 / 1363461507087997$

Desjarlais, R., Eisenberg, L., Good, B., \& Kleinman, A. (1995). World Mental Health. Problems and Priorities in Low-Income Countries. New York: Oxford University Press.

Draguns, J. G., \& Tanaka-Matsumi, J. (2003). Assessment of psychopathology across and within cultures: Issues and findings. Behaviour Research and Therapy, 41, 755-776. doi:10.1016/S0005-7967(02)00190-0

Duddu, V., Isaac, M. K., \& Chaturvedi, S. K. (2006). Somatization, somatosensory amplification, attribution styles and illness behavior: A review. International Review of Psychiatry, 1, $25-33$.

Eagly, A. (1987). Sex differences in social behavior: A social role interpretation. Hillsdale, NJ: Erlbaum.

Eisenberg, L. (1977). Disease and Illness: distinctions between professional and popular ideas of sickness. Culture, Medicine, and Psychiatry, 1, 9-23. 
Eisenbruch, M. (1990). Classification of supernatural and natural causes of mental distress. Development of a Mental Distress Explanatory Model Questionnaire. Journal of Nervous and Mental Disease, 178, 712-719.

Fazel, M., Wheeler, J., \& Danesh, J. (2005). Prevalence of serious mental disorder in 7000 refugees resettled in western countries: A systematic review. Lancet, 365, 1309-1314. doi:10.1016/S0140-6736(05)61027-6

Fozdar, F. (2009). 'The Golden Country': Ex-Yugoslav and African refugee experiences of settlement and 'depression'. Journal of Ethnic and Migration Studies, 35, 1335-1352. doi:10.1080/13691830903123120

Gerritsen, A. A. M., Bramsen, I., Devillé, W., van Willingen, L. H. M., Hovens, J. E., \& van der Ploeg, H. M (2006). Use of health care services by Afghan, Iranian, and Somali refugees and asylum seekers living in The Netherlands. European Journal of Public Health, 16, 394-399. doi:10.1093/eurpub/ck1046

Groleau, D., Young, A., \& Kirmayer, L. J. (2006). The McGill Illness Narrative Interview (MINI): An interview schedule to elicit meanings and modes of reasoning related to illness experience. Transcultural Psychiatry, 43, 671-691. doi: $10.1177 / 1363461506070796$

Guerin, B., Guerin, P., Diirye, R. O., \& Yates, S. (2004). Somali conceptions and expectations concerning mental health: Some guidelines for mental health professionals. New Zealand Journal of Psychology, 33, 59-67.

Hammond, L., Awad, M., Dagane, A., Hansen, P., Horst, C., Menkhaus, K., \& Obare, L. (2011). Cash and compassion: The role of the Somali diaspora in relief, development and peacebuilding [study report]. Report of a study Commissioned by UNDP Somalia. Retrieved from: http://www.hiiraan.com/2011/May/Cash-and-Compassion-Draft-for-comments.pdf 
Helander, B. (1995). Disability as incurable illness: Health, process, and personhood in southern Somalia. In Ingstad, B. \& Reynolds Whyte, S. (eds.), Disability and Culture, pp. 73-93. Berkeley: University of California Press.

IBM Corporation (2013). IBM SPSS Statistics for Windows, Version 22.0. Armonk, New York: IBM Corporation.

Ikwuka, U., Galbraith, N., \& Nyatanga, L. (2014). Causal attribution of mental illness in southeastern Nigeria. International Journal of Social Psychiatry, 60(3), 274-279.

Jasinskaja-Lahti, I., Liebkind, K., \& Perhoniemi, R. (2006). Perceived discrimination and wellbeing: A victim study of different immigrant groups. Journal of Community \& Applied Social Psychology, 16, 267-284. doi:10.1002/casp.865

Johnsdotter, S., Ingvarsdotter, K., Östman, M. \& Carlbom, A. (2011). Koran reading and negotiation with jinn: Strategies to deal with mental ill health among Swedish Somalis. Mental Health, Religion \& Culture, 14, 741-755. doi:10.1080/1364676.2010.521144

Kleinman, A. (1980). Patients and healers in the context of culture. Berkeley: University of California Press.

Kleinman, A., Eisenberg, L., \& Good, B. (1978). Clinical lessons from anthropologic and crosscultural research. Annals of Internal Medicine, 88, 251-258.

Kuittinen, S., Punamäki, R-L., Mölsä, M., Saarni, S. I., Tiilikainen, M., \& Honkasalo, M-L. (2014). Depressive symptoms and their psychosocial correlates among older Somali refugees and native Finns. Journal of Cross-Cultural Psychology, 9(45), 1434-1452. doi:10.1177/0022022114543519

Lawrence, V., Murray, J., Banerjee, S., Turner, S., Sangha, K., Byng, R..., Macdonald, A. (2006). Concepts and causation of depression: A cross-cultural study on the beliefs of older adults. The Gerontologist, 46, 23-32. 
Lewis, I. M. (1998). Saints and Somalis: Popular Islam in a clan-based society. Lawrenceville, NJ: The Red Sea Press.

Lewis, I. M. (2008). Understanding Somalia and Somaliland: Culture, History, Society. London: Hurst \& Company.

Lim, A., Hoek, H. W., \& Blom, D. (2015). The attribution of psychotic symptoms to jinn in Islamic patients. Transcultural Psychiatry, 52(1), 18-32. doi:10.1177/1363461514543146

Loewenthal, D., Mohamed, A., Mukhopadhyay, S., Ganesh, K., \& Thomas, R. (2012). Reducing the barriers to accessing psychological therapies for Bengali, Urdu, Tamil and Somali communities in the UK: Some implications for training, policy and practice. British Journal of Guidance \& Counselling, 40(1), 43-66.

Matsumoto, D., \& Yoo, S.H. (2006). Toward a new generation of cross-cultural research. Perspectives on Psychological Science, 1, 234-250. doi:10.1111/j.17456916.2006.00014.x

McCabe, R., \& Priebe, S. (2004). Explanatory models of illness in schizophrenia: Comparison of four ethnic groups. British Journal of Psychiatry, 185, 25-30.

McCrone, P., Bhui, K., Craig, T., Mohamud, S., Warfa., N., Stansfeld, S. S....Curtis, S. (2005). Mental health needs, service use and costs among Somali refugees in the UK. Acta Psychiatrica Scandinavica, 111, 65-77.

Moussavi, S., Chatterji, S., Verdes, E., Tandon, A., Patel, V., \& Ustun, B. (2007). Depression, chronic diseases, and decrements in health: Results from the World Health Surveys. The Lancet, 370, 851-858.doi:10.1016/S0140-6736(07)61415-9

Mölsä, M., Hjelde, K. H., \& Tiilikainen, M. (2010). Changing conceptions of mental distress among Somalis in Finland. Transcultural Psychiatry, 47, 276-300. doi: $10.1177 / 1363461510368914$ 
Mölsä, M., Kuittinen, S., Tiilikainen, M., Honkasalo, M.-L., \& Punamäki, R.-L. (2016). Mental health among older refugees: the role of trauma, discrimination, and religiousness. Aging \& Mental Health,1-9. Published online 15 Apr 2016. doi:

$10.1080 / 13607863.2016 .1165183$

Mölsä, M., Punamäki, R-L., Saarni, S. I., Tiilikainen, M., Kuittinen, S., \& Honkasalo, M-L. (2014). Mental and somatic health and pre- and post-migration factors among older Somali refugees in Finland. Transcultural Psychiatry, 51(4), 499-525. doi: $10.1177 / 1363461514526630$

Mölsä, M., \& Tiilikainen, M. (2008). Somalialaisten maahanmuuttajien ikääntymisen ja sairastamisen kokemuksia Suomessa [Experiences of Somali migrants on ageing and illness in Finland]. Sosiaalilääketieteellinen Aikakauslehti [Journal of Social Medicine] $45,74-87$.

Palmer, D. (2006). 'Imperfect prescription': The perceptions, mental health experiences and challenges faced by the Somali community in the London Borough of Camden and service responses to them. Primary Care Mental Health, 4, 45-56.

Pavlish, C.L., Noor, S., \& Brandt, J. (2010). Somali immigrant women and the American health care system: Discordant beliefs, divergent expectations, and silent worries. Social Science and Medicine, 71, 353-361.

Phillips, M. R., Li, Y., Stroup, T. S., \& Xin, L. (2000). Causes of schizophrenia reported by patients' family members in China. The British Journal of Psychiatry, 177, 20-25. doi:10.1192/bjp.177.1.20

Pirkola, S. P., Isometsä, E., Suvisaari, J., Aro, H., Joukamaa, M., Poikolainen, K., Koskinen, S., .. \& Lönnqvist, J. K. (2005). DSM-IV mood-, anxiety- and alcohol use disorders and their comorbidity in the Finnish general population. Results from the Health 2000 Study. 
Social Psychiatry and Psychiatric Epidemiology, 40, 1-10. doi:10.1007/s00127-0050848-7

Poortinga, Y. H., Van de Vijver, F. J. R., Joe, R. C., \& van de Koppel, J. M. H. (1987). Peeling the onion called culture: A synopsis. In C. Kagitcibasi (Ed.), Growth and progress in cross-cultural psychology, pp. 22-34. Lisse, Netherlands: Swets \& Zeitlinger.

Reynolds Whyte, S. (1997). Questioning Misfortune. The Pragmatics of Uncertainty in Eastern Uganda. Cambridge: Cambridge University Press.

Ryder, A. G., Yang, J., Zhu, X., Yao, S., Yi, J., Heine, S. J., \& Bagby, M. R. (2008). The cultural shaping of depression: Somatic symptoms in China, psychological symptoms in North America? Journal of Abnormal Psychology, 117, 300-313. doi:10.1037/0021843X.117.2.300

Shorter, E. (1993). From Paralysis to Fatigue: A history of Psychosomatic Illness in the Modern Era. New York: Free Press.

Slikkerveer, L. J. (1990). Plural medical systems in the Horn of Africa: The legacy of "Sheikh" Hippocrates. London: Kegan Paul International.

Silveira, E., \& Ebrahim, S. (1995). Mental health and health status of elderly Bengalis and Somalis in London. Age and Ageing, 24, 474-480. doi:10.1093/ageing/24.6.474

Simon, G. E., VonKorff, M., Piccinelli, M., Fullerton, C., \& Ormel, J., (1999). An international study of the relation between somatic symptoms and depression. The New England Journal of Medicine, 341(18), 1329-1335.

Somalis in Helsinki (2013). New York: Open Society Foundations. Available at http://www.opensocietyfoundations.org/sites/default/files/somalis-helsinki-20131121.pdf 
Sorsdahl, K. R., Flisher, A. J., Wilson, Z., \& Stein, D. J. (2010). Explanatory models of mental disorders and treatment practices among traditional healers in Mpumulanga, South Africa. African Journal of Psychiatry, 3, 284-290.

Statistics Finland. (2010). Työssäkäynti 2008 [Employment 2008. E-publication]. Helsinki, Finland: Statistics Finland. Retrieved from http://www.stat.fi/til/tyokay/2008/01/tyokay_2008_01_2010-04-20_fi.pdf

Statistics Finland. (2013a). Population structure [e-publication]. Helsinki, Finland: Statistics Finland. Retrieved from http://tilastokeskus.fi/til/vaerak/2012/vaerak_2012_2013-0322_tie_001_en.html?ad=notify

Statistics Finland. (2013b). Background country and origin according to age and sex by region 1990-2013. Retrieved from http://pxweb2.stat.fi/Dialog/varval.asp?ma=045_vaerak_tau_200_en\&ti=Background+co untry+and+origin+according+to+age+and+sex+by+region+1990++2012\&path=../Database/StatFin/vrm/vaerak/\&lang=1\&multilang=en

Sterlin, C. (2006). Pour une approche interculturelle du concept de santé. Ruptures, revue transdisciplinaire en santé, 1, 112-121.

Suvisaari, J., Ahola, K., Kiviruusu, O., Korkeila, J., Lindfors, O., Mattila, A., Markkula, N., ... Viertiö, S. (2012). Psyykkiset oireet ja mielenterveyden häiriöt [Psychiatric symptoms and mental health disorders]. In Koskinen, S., Lundqvist, A., \& Ristiluoma, N. (Eds.) Terveys, toimintakyky ja hyvinvointi Suomessa 2011 [Health, ability to function, and wellbeing in Finland in 2011]. National Institute for Health and Welfare.

Tiilikainen, M. (2003). Arjen islam. Somalinaisten elämää Suomessa [Everyday Islam. Everyday Life of Somali Women in Finland]. Tampere: Vastapaino. 
Tiilikainen, M. (2010). Spirits and the human world in northern Somalia. In Hoehne, M. \& Luling, V. (Eds.), Milk and Peace, Drought and War. Somali Culture, Society, and Politics, pp. 163-184. London: Hurst \& Company.

Tiilikainen, M. (2011). Failed diaspora: Experiences of Dhaqan Celis and mentally ill returnees in Somaliland. Nordic Journal of African Studies, 20(1): 71-89.

Tiilikainen, M., \& Koehn, P. H. (2011). Transforming the boundaries of health care: Insights from Somali migrants. Medical Anthropology, 30, 518-544. doi:10.1080/01459740.2011.577288

Tikkinen, K. A. O., Leinonen, J. S., Guyatt, G. H., Ebrahim, S., \& Järvinen, T. (2012). What is a disease? Perspectives of the public, health professionals, and legislators. British Medical Journal Open. doi:10.1136/bmjopen-2012-001632

Weiss, M. G. \& Somma, D. (2007). Explanatory models in psychiatry. In Bhugra, D. \& Bhui, K. (eds.), Textbook of Cultural Psychiatry, pp. 127-140. New York: Cambridge University Press.

White, G. M. (1982). The role of cultural explanations in "somatization" and "psychologization". Social Science and Medicine, 16, 1519-1530.

Williams, B., \& Healy, D. (2001). Perceptions of illness causation among new referrals to a community mental health team: “explanatory model”” or "exploratory map"? Social Science \& Medicine, 53, 465-476.

World Health Organization. (2010). A Situation Analysis of Mental Health in Somalia [edocument]. Retrieved from http://reliefweb.int/sites/reliefweb.int/files/resources/111AEF992F74A43FC125782B0048 4E8D-Full_Report.pdf 
World Bank (2013). Life expectancy at birth, total (years) [table]. The World Bank Group.

Retrieved from http://data.worldbank.org/indicator/SP.DYN.LE00.IN 
Table 1

Principal Axis Factor Analysis of the Beck Depression Inventory Items $(\mathrm{N}=128)$

\begin{tabular}{|c|c|c|}
\hline Item & Somatic-affective & Cognitive \\
\hline Depressed mood & .676 & .086 \\
\hline Hopelessness & .434 & .249 \\
\hline Sense of failure & .140 & .417 \\
\hline Dissatisfaction & .301 & .554 \\
\hline Guilt & .226 & .635 \\
\hline Feeling of punishment & .752 & .016 \\
\hline Self-dislike & -.122 & .639 \\
\hline Self-blame & .028 & .473 \\
\hline Suicidal ideation & -.125 & .371 \\
\hline Crying & .740 & -.100 \\
\hline Irritability & .730 & .040 \\
\hline Loss of interest in others & .735 & .041 \\
\hline Indecisiveness & .833 & .004 \\
\hline Body image change & .122 & .513 \\
\hline Difficulties working & .570 & .177 \\
\hline Insomnia & .930 & -.113 \\
\hline Fatigue & .861 & -.112 \\
\hline Loss of appetite & .900 & -.039 \\
\hline Loss of weight & .467 & .105 \\
\hline Somatic preoccupation & .756 & -.105 \\
\hline Loss of interest in sex & .392 & .021 \\
\hline Factor intercorrelation & \multicolumn{2}{|c|}{.315} \\
\hline Cronbach's alpha & .73 & .93 \\
\hline
\end{tabular}

Note. Items assigned to somatic-affective and cognitive symptom categories are shown in bold. 
Table 2

Demographic Variables

Gender

Women

Men

Age (years)

$50-59$

$60-69$

$70-80$

Civic status

Married

Divorced

Widowed

Single

Education

No education

Vocational training/courses

Polytechnic / University

Other

Employment status

Full time employment

Part time employment

Unemployed

Retired

Other

Current residency type

Finnish nationality

Permanent residency permit

Humanitarian law

Family member status
10

75

59

53

41

78

61

43

7

34

6

79

12

33

3

62

9

26

2

86

23

17

4

66

18

13

3

3

49

18

2

8

3

38

14

2

25

20

61

48

20

16

9

$\%$

9

1

(1)

4

.


Other

Time of residency in Finland

$0-5$ years

$6-10$ years

11-20 years

Language proficiency

No

Yes
12

9

36

40

53

61

34
27

31

41

48

27

Note. Some percentages do not add up to $100 \%$ due to rounding and missing values. 
Table 3

Classification of Mental Health Attributions and Frequencies and Percentages of Attribution Categories

\begin{tabular}{|c|c|c|c|}
\hline \multirow[t]{2}{*}{ Attribution category } & \multirow[t]{2}{*}{ Examples } & \multicolumn{2}{|c|}{ Participants $(\mathrm{N}=128)$} \\
\hline & & $\mathrm{n}$ & $\%$ \\
\hline \multirow[t]{3}{*}{ Life experiences } & Poverty & \multirow[t]{3}{*}{73} & \multirow[t]{3}{*}{57} \\
\hline & War & & \\
\hline & Hard life & & \\
\hline \multirow{3}{*}{$\begin{array}{l}\text { Interpersonal } \\
\text { attributions }\end{array}$} & Family problems & \multirow[t]{3}{*}{67} & \multirow[t]{3}{*}{52} \\
\hline & Loneliness & & \\
\hline & Maseyrka & & \\
\hline \multirow[t]{4}{*}{ Religious attributions } & Jinn & \multirow[t]{4}{*}{52} & \multirow[t]{4}{*}{41} \\
\hline & God's will & & \\
\hline & Disease caused by God & & \\
\hline & Losing one's religious belief & & \\
\hline \multirow{3}{*}{$\begin{array}{l}\text { Psychological } \\
\text { attributions }\end{array}$} & Gambling & \multirow[t]{3}{*}{33} & \multirow[t]{3}{*}{26} \\
\hline & Excessive thinking & & \\
\hline & Worrying & & \\
\hline \multirow[t]{3}{*}{ Somatic attributions } & Diabetes & \multirow[t]{3}{*}{30} & \multirow[t]{3}{*}{23} \\
\hline & Insomnia & & \\
\hline & Substance use & & \\
\hline
\end{tabular}


Table 4

Spearman Correlations between Attribution Categories

\begin{tabular}{lcccc}
\hline & Life experiences & Interpersonal & Religious & Somatic \\
\hline Interpersonal & .120 & & & \\
Religious & .142 & $.250 * *$ & & \\
Somatic & -.046 & $-.208^{*}$ & $-.283 * *$ & \\
Psychological & $-.307 * *$ & $-.186^{*}$ & $-.327 * *$ & .050 \\
\hline
\end{tabular}

Note. $\mathrm{N}=128$. The values of the attribution categories range from 0 to 3 .

${ }^{*} p<.05$, two-tailed; $* * p<.01$, two-tailed. 
Table 5

Distributions of Attribution Categories According to Gender, Age, Education, Psychiatric

Diagnosis/Treatment History, and Proxy Indicators of Acculturation (percentages and frequencies of the attributions, and $\chi^{2}$-values)

\begin{tabular}{|c|c|c|c|c|c|c|}
\hline \multirow{2}{*}{ 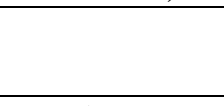 } & \multicolumn{2}{|c|}{ Life experiences } & \multicolumn{2}{|c|}{ Socio-religious } & \multicolumn{2}{|c|}{ Intra-individual } \\
\hline & $\%$ & $\mathrm{n}$ & $\%$ & $\mathrm{n}$ & $\%$ & $\mathrm{n}$ \\
\hline \multicolumn{7}{|l|}{ Gender } \\
\hline Male & 53 & 28 & 53 & 28 & 59 & 31 \\
\hline Female & 59 & 44 & 72 & 54 & 29 & 22 \\
\hline$\chi^{2}$-values & .43 & & 4.96 & & $10.88 *$ & \\
\hline \multicolumn{7}{|l|}{ Age } \\
\hline $50-59$ & 57 & 49 & 65 & 56 & 38 & 33 \\
\hline $60-69$ & 54 & 20 & 60 & 22 & 49 & 18 \\
\hline $70-79$ & 60 & 3 & 80 & 4 & 40 & 2 \\
\hline$\chi^{2}$-values & .12 & & .94 & & 1.13 & \\
\hline \multicolumn{7}{|l|}{ Education } \\
\hline None & 54 & 45 & 68 & 57 & 42 & 35 \\
\hline Vocational & 52 & 12 & 57 & 13 & 22 & 5 \\
\hline University & 82 & 14 & 47 & 8 & 59 & 10 \\
\hline$\chi^{2}$-values & $5.09^{\dagger}$ & & 3.11 & & $5.78^{\dagger}$ & \\
\hline \multicolumn{7}{|c|}{$\begin{array}{l}\text { Psych. diagnosis } \\
\text { /treatment }\end{array}$} \\
\hline No & 55 & 61 & 68 & 74 & 38 & 42 \\
\hline Yes & 65 & 11 & 47 & 8 & 65 & 11 \\
\hline$\chi^{2}$-values & .57 & & 2.46 & & $4.37 *$ & \\
\hline \multicolumn{7}{|l|}{ Finnish } \\
\hline \multicolumn{7}{|l|}{ Nationality } \\
\hline No & 53 & 55 & 65 & 67 & 42 & 43 \\
\hline Yes & 6 & 17 & 60 & 15 & 40 & 10 \\
\hline$\chi^{2}$-values & 1.74 & & .22 & & .033 & \\
\hline \multicolumn{7}{|c|}{ Years in Finland } \\
\hline $0-5$ & 54 & 19 & 71 & 25 & 37 & 13 \\
\hline $6-10$ & 45 & 18 & 63 & 25 & 40 & 16 \\
\hline $11-20$ & 66 & 35 & 60 & 32 & 45 & 24 \\
\hline$\chi^{2}$-values & 4.18 & & 1.18 & & .62 & \\
\hline \multicolumn{7}{|l|}{$\begin{array}{l}\text { Language } \\
\text { proficiency }\end{array}$} \\
\hline No & 54 & 33 & 64 & 39 & 34 & 21 \\
\hline Yes & 65 & 22 & 65 & 22 & 44 & 15 \\
\hline$\chi^{2}$-values & 1.00 & & .011 & & .87 & \\
\hline
\end{tabular}

Note. Degrees of freedom vary between 1 and 2 .

${ }^{\dagger} p<.10$, two-tailed; $* p<.05$, two-tailed; ** $p<.01$, two-tailed. 